\title{
A method of building an aggregated indicator of air-pollution impacts
}

\author{
T. Goger \& R. Joumard \\ Inrets, Laboratoire Transports et Environnement, Bron Cedex, France
}

\begin{abstract}
We intend to build a global environmental impact indicator of air pollution to assess transport infrastructures and technologies. This indicator should be simple and transparent to facilitate its use in decision-making. The intention is for the indicator to resemble the Global Warming Potential (GWP), which establishes a relationship between the emission of six greenhouse gases and the average temperature increase of the Earth. The indicator will therefore permit estimation of the global environmental impact of transport-generated air pollution, while simultaneously conserving the value of the environmental impact of each type of air pollution and the emission assessment. This work is based on an impact typology, a set of indicators, and an aggregation architecture of atmospheric pollution.
\end{abstract}

The typology is established as a combination of the specific and homogenous characteristics of each type of pollution in terms of pollutant, impact mechanism, target and environmental impact. To ensure exhaustiveness and non-redundancy, 10 types of air pollution impact are proposed: greenhouse effect, ozone depletion, direct ecotoxicity (this type of pollution excludes greenhouse effects on nature, ozone depletion, eutrophication, acidification and photochemical pollution), eutrophication, acidification, photochemical pollution, restricted direct health effects (not taking into account welfare, and excluding the effects on health of the greenhouse effect, ozone depletion, acidification and photochemical pollution), sensitive pollution (annoyance caused by odours and fumes), and degradation of common and historical man-made heritage.

Indicators similar to GWP can be identified in the literature for each type of atmospheric pollution, except for the degradation of common and historical man-made heritage, for which the financial cost of conservation could be used. However, these indicators do not seem to have achieved wide scientific consensus, except for GWP, which may make it necessary to continue research in this field.

Aggregating the different indicators is proposed by using an architecture composed of two structures that aggregate types of air pollution. One is based on the target affected, whereas the second has three dimensions, i.e. targets, space and time. This architecture allows the indicator's users to establish a hierarchy of concerns for each type of atmospheric pollution.

Keywords: air pollution, environmental impact, emissions, target, typology, aggregation, indicator. 


\section{Introduction}

Transport causes myriad environmental impacts that stir increasing concern among specialists, decision-makers and society as a whole. Given the diversity and complexity of the impacts, the procedures used for putting them into perspective vary considerably. A simple, transparent and synthetic evaluation of these impacts would facilitate decision-making. Assessing the environmental impacts of atmospheric pollutants is part of this process.

We propose to identify the different categories of environmental impacts caused by atmospheric pollution and characterise them by an indicator based on scientific knowledge, using as reference the global warming potential proposed by GIEC [1]. This assesses the environmental impacts of the greenhouse effect simply and synthetically, via the predictable increase of temperature due to the emission of six pollutants, without modelling concentrations, and then the chain of impacts (disturbances of climatic and ecological balances, etc.).

We then propose to aggregate these indicators in a global indicator in order to answer pertinent questions such as "is gasoline more pollutant than diesel fuel?", and "what is the progression of the environmental impacts of atmospheric pollutants emitted by road transport in France?" An attempt will be made to base this aggregation of indicators as much as possible on scientific knowledge, taking care not to step outside the legitimacy of the scientific community, for example, to weight impacts such as sensitive pollution, the greenhouse effect and health effects. Aggregating indicators should also mirror social concerns relating to air pollution.

\section{Air-pollutant impact typology}

A typology of air pollution will be formulated as a function of the different categories of environmental impact affected by atmospheric pollutants emitted by transport, before evaluating them with an indicator. This typology is based on physical, chemical, biological, ecological knowledge, etc. of atmospheric pollution. Each type of pollution corresponds to a category of homogenous environmental impacts defined by a specific combination of pollutants, impact mechanisms, targets and impacts. We seek to ensure that the typology is as accurate and exhaustive as possible, while at the same time reducing redundancies.

Three targets, defined as a group of homogenous receptors, are mainly affected by air quality: nature understood as ecosystems, i.e. the association between a physicochemical and abiotic (the biotope) environment and a living community characteristic of the latter (the biocenosis), humankind which we extract from nature and focus on its health as defined by the World Health Organisation [2], and man-made heritage for which a distinction is made between common buildings and historic ones. A fourth item is added to these three targets, i.e. the Earth, which is not a true target since it covers all the targets: the three previous targets and physical environments such as the atmosphere and the oceans. Therefore it is considered as a pseudo target. 
An impact corresponds to the response of a target exposed to a condition of air quality. The impacts vary greatly and often form successions and chains of impacts. Thus greenhouse gas emissions lead first to global climatic warming, from which stem among other impacts such as the rise in sea levels in turn leading to flooding liable to cause the displacement of human populations and health effects, and modifications of ecosystems liable to cause loss of biodiversity.

Guinee et al [3] distinguished several categories of environmental impact: the greenhouse effect, ozone depletion, photochemical pollution, acidification, eutrophication, health effects, and effects on nature. All these categories provide a relatively wide view of our air pollution typology, though leave out three categories of environmental impact to which atmospheric pollutants contribute: sensitive pollution, and the degradation of common and historic man-made heritage. However, a certain number of redundancies can be observed: health impacts due to photochemical pollution, ozone depletion and the greenhouse effect are, for example, redundant with health effects. To avoid redundancies while covering all the environmental impacts caused by the different pollutant gases emitted by transport, we redefine ten categories of impact:

- The greenhouse effect or more exactly the increase of greenhouse gases [1].

- Ozone depletion: halogen compounds react with stratospheric ozone and lead to the depletion of the ozone layer. Although theoretically under control, this impact has not disappeared and is thus still of great interest (Académie des sciences [4]).

- Photochemical pollution: nitrogen oxides and volatile organic compounds react to form tropospheric ozone outside urban centres, toxic for humankind and nature (Derwent et al [5]).

- Acidification: nitrogen oxide and sulphur dioxide are transformed into acid compounds that acidify the natural environment up to $1,000 \mathrm{~km}$ away from the point of emission (Potting et al [6]).

- Eutrophication: nitrogen oxides contribute towards increasing plant biomass whose excessive development leads to anoxia in aquatic environments, then harms fauna and flora (Finnveden and Östlund [7]).

- Direct restricted health effects: effects on human health, which is restricted since it does not include harm to welfare and psychological aspects (integrated in sensitive pollution), and direct since it only considers effects due to exposure to primary pollutants. Health impacts due to secondary pollutants (acidification, photochemical pollution, etc.) are regulated by impact laws of different natures (Campagna et al [8]).

- Direct ecotoxicity: primary pollutants affecting human health can also affect nature (Huijbregts [9]).

- Sensitive pollution: perceived by our senses, mainly sight and smell, it is composed of smoke, soiling and odours (Moch and Roussel [10]).

- Degradation of common man-made heritage: this is mainly due to the affects of particles and corrosive products. It incorporates the impacts of photochemical pollution and acidification on buildings (Diren et al [11]). 
- Degradation of historic man-made heritage: this is separated from the previous category as the impact is not chiefly sensitive or economic, but cultural and irreversible insofar as each work is unique and impossible to recreate identically. There is also the factor of loss of know-how in certain cases (Diren et al [11])

We have decided not to take into account radioactive pollution in our typology since it is caused by nuclear power production and is not closely linked to the transport sector. The characteristics of these impacts on the environment are also of a very different nature.

\section{Air-pollution indicators}

For each of the ten impact categories mentioned above, one or more impact indicators are required before their aggregation can be considered. These indicators must necessarily result from scientific knowledge of impact mechanisms and thus from the scientific discipline associated with each impact. However, specific communities are more or less well developed and structured vis-à-vis these impacts as a function of the progress made in obtaining knowledge and financial and human investment.

Thus a large number of scientists from a wide range of disciplines work on the greenhouse effect, aided by strong internal cooperation, particularly within GIEC. This organisation provides sound and synthetic information, in addition to an indicator known as potential global warming (PGW), which is the subject of widespread international agreement (GIEC [1]). This indicator establishes a simple relation (weighted total) between the emission of six greenhouse gases and the average increase of the Earth's temperature, which is the initial impact of the chain of impacts of the greenhouse effect. It permits evaluating the initial impact of any transport system or sub-system.

On the other hand, specialists in sensitive pollution seem to be fewer and more cut off from each other. The literature in the field is less abundant. What is more, there do not appear to be any indicators linking an annoyance level to a quantity of smoke, soiling or odour emitted. Nonetheless, chemists have developed a global potential odour indicator (PO), built in the same way as the PGW, that establishes a relation between an intensity of odour and a quantity of pollutant emitted (Guinee et al [3]). The global odour is given by the total emissions of pollutants weighted by a coefficient corresponding to an olfactive perception threshold. However, this indicator has not achieved consensus since many specialists underline the fact that sensitive pollution is characterised by annoyance, which is not directly related to the intensity of an odour, but far more to its variation through time. There is no similar indicator for sensitive visual pollution. Despite this we consider opting for odours as the indicator for sensitive pollution for want of a better one.

As for the degradation of common and historic man-made heritage, there is a lack of both specialists and literature. However, the diversity and extent of impacts are more limited, since they are essentially physicochemical impacts that 
affect materials, giving rise to general scientific consensus. Economic theories are moreover well-adapted for assessing the commercial goods and services linked to maintaining buildings, which explains the widespread use of economic indicators for evaluating environmental impacts of pollution on buildings (O'Connor and Spash [12]). These indicators are very simple and represent final impacts rather than intermediate ones. Nonetheless they do not establish a link between the emission of pollutants and the intensity of degradation. They also make use of more or less disputed concepts such as agreement to pay, to give an economic expression to the value of a heritage that has no relation to any market, for example, a historic monument whose value is above all cultural (Spash and Hanley [13]). Because of these criticisms, we consider selecting no indicator for assessing the environmental impacts of degradation to common and cultural man-made heritage.

The field of health has many specialists, is well structured and is the source of high quality literature on indicators (Campagna et al [8]). However, the great heterogeneity of the impacts dealt with by different specialities has made it difficult to develop a synthetic indicator of health impacts. To our knowledge, there is only one global health effect indicator, i.e. potential toxicity (PT) which corresponds to the total pollutant emissions weighted by the toxicity of each pollutant (Huijbregts [14]). However, this indicator has inspired very little agreement. Given the importance of this impact, we consider calling on a college of specialists to build a new direct restricted health effect indicator.

The same observations apply to direct ecotoxicity, for which an indicator similar to PT exists, called potential ecotoxicity (PET) (Huijbregts, [9]), though this indicator is not subject to general consensus either.

Lastly, although the problems of eutrophication, acidification, photochemical pollution and ozone depletion are dealt with by a large number of specialists, mostly biologists, ecologists, chemists and health experts, these appear to be dispersed. The literature takes stock of the physicochemical mechanisms and ecological and health impacts of these four impacts. Works performed by chemists also permit proposing synthetic indicators, built in the same way as the PGW, i.e. potential eutrophication (PE) (Huijbregts [15]), potential acidification (PA) (Huijbregts [15]), the photochemical oxidant creation potential (POCP) (Derwent et al [5]), and the ozone depletion potential (ODP) (Solomon and Albritton [16]). Once again, these indicators are not subject to widespread consensus.

Consequently the literature shows that an impact indicator exists for each type of impact. The great majority of these indicators are built according to the same structure as that used for the PGW, with the exception of degradation of common and historic man-made heritage, which is assessed on the basis of an economic indicator. They generally establish a relationship between pollutant emissions and an impact characteristic of a type of impact, which permits the assessment in a simple way of the contribution made by transport to each type of impact. The impact chosen as characteristic is systematically situated at the start of the impact chain, implying the indirect hypothesis that the intensity of the final impacts is proportional to that of the initial impact, which could hardly be a more 
approximate approach. Despite this fact, they are much used today for analysing product lifecycles, and they appear to be the only tools available at present for performing an aggregated assessment of types of atmospheric pollution caused by transport.

\section{Aggregation architecture used for air pollution}

Due to the diversity of types of air pollution it is not possible to make a global assessment of all its impacts on the environment without aggregating the different types of impact (Faucheux and O'Connor [17]). However, aggregating or arbitrating between types of impact as different as the greenhouse effect and the degradation of common and historic man-made heritage, or health impacts and sensitive pollution, depends on personal and collective preferences. To avoid making use of often personal, non-justified and opaque procedures for synthesising data, we propose formulating an architecture for aggregating types of atmospheric pollution, thus of indicators. This architecture should help the user of the indicator to aggregate the different types of impact and identify the types of atmospheric pollution they consider the most important.

Indeed, only the society concerned or its representatives can perform such arbitration legitimately (Funtowicz et al [18]). Scientists can only facilitate the expression of such arbitrations and in no way can they pronounce as scientists on the predomination of such and such an impact.

\subsection{Impact categories socially distinguished-based aggregation structure}

In this case the aggregation of types of impact is carried out according to the preference given to each impact category socially distinguished.

According literature, four targets affected by atmospheric pollution (the Earth, nature, humankind, man-made heritage) are well socially distinguished, this is so for only seven types of impact: the greenhouse effect, ozone depletion, effects on ecosystems, health effects, sensitive pollution, the degradation of common anthropic heritage, and the degradation of cultural man-made heritage (Weber and Vanolli [19]).

A type of impact distinguished socially can sometimes correspond to several types of scientifically established impact. This leads, occasionally, to switching a social or political aggregation, with an aggregation established by the scientific community. Thus direct ecotoxicity, acidification, eutrophication and photochemical pollution must be aggregated using this process in effects on ecosystems. This aggregation can thus only be partial.

This distinction is also rather fragile since it is based exclusively on the knowledge of terms and not their specific meaning.

This process, which lacks legitimacy, and the weakness of social distinction leads us to propose an alternative aggregation structure, in order to make our aggregation architecture more robust. 


\subsection{Target, spatial and local dimensions-based aggregation structure}

This second aggregation structure relies on the target dimension and two other very well-known dimensions: time and space, with the aim of distinguishing types of impact that are not considered as social if viewed solely from the standpoint of targets.

We propose to make use of surveys and other participatory methods such as forums to define the number of spatiotemporal classes and their limits (short, medium and long term, local, regional, global), and to know the level of social concern corresponding to each dimension.

Then, we create combined levels of social concern corresponding to the three dimensions. Thirty six social weights can thus be elaborated.

Lastly, we make the social weights corresponding with the ten types of scientifically defined air-pollution impacts. Since one type of impact corresponds to a target, a time frame (short, medium or long term) and a geographic characteristic (global, regional, local), we suggest to let specialists sharing the combined levels of social concern corresponding to the three dimensions at the types of scientifically defined impacts level.

We can also obtain a weight for the ten impact categories based on social concern. This aggregation structure makes it possible to increase on the one hand robustness because social weights are based on well-known dimensions, and on the other hand, on precision because the distribution of the social weights at the impact categories level is based the contribution of specialists knowing the characteristics of these last.

\section{Conclusion}

The air-pollution impacts typology proposed here contributes towards the scientific and transparent identification of the different types of impact to be taken into account in an air pollution indicator. An indicator must correspond to each type of impact characterised by a specific environmental impact category, but this indicator must result from collaboration between specialists in this category of impact. Consequently, indicators can be identified by type of impact, although certain indicators do not enjoy widespread scientific consensus. We propose to aggregate these types of impact and their corresponding indicators by using an indirect method that associates spatiotemporal and target dimensions. This architecture permits framing the aggregation of types of air-pollution impacts in a scientific process, by helping the user to assign a preference to each of the types of impact defined scientifically, including in the case where they are not socially distinguished. This method will permit building a global impact indicator for air-pollution, keeping all the input data (from the emissions to the global impact), through a robust structure opposite the addition or the modification of the indicators and the weighting coefficients, and above all flexible allowing calculating the indicator at specific level (as short-term and local level for instance) or at a more global level. 


\section{References}

[1] GIEC (2001): Bilan 2001 des changements climatiques - Les éléments scientifiques. GIEC, $90 \mathrm{p}$.

[2] WHO (1999): Environment health Indicators - Framework and methodologies. OMS, Geneva.

[3] Guinee J.B., M. Gorree \& R. Heiungs (2002): Handbook on Life Assessment. An operational guide to the ISO standard. Kluwer Academic, London, UK, $704 \mathrm{p}$.

[4] Académie des sciences (1998): L'ozone stratosphérique. Tec \& Doc, Paris, $270 \mathrm{p}$.

[5] Derwent N.G., M.E. Jenkin \& S.M. Saunders (1998): Photochemical ozone creation potentials for organic compounds in Northwest Europe calculated with a master chemical mechanism. Atm. Env., vol 32, p. 24292441.

[6] Potting J., W. Schöpp \& K. Blok (1998): Comparison of the acidifying impact from emissions with different regional origin in life-cycle Assessment. J. Hazardous Materials, vol 61, p. 155-162.

[7] Finnveden G. \& P. Östlund (1997): Eutrophisation as an impact category State of the art and research needs. J. Life Cycle Anal., vol 4, n 6, p. 311314.

[8] Campagna D., S. Cassadou, C. Declercq, D. Eilstein, L. Filleul, A. Le terre, S. Medina, C. Nunes, L. Pascal, H. Prouvost, P. Saviuc, A. Zeghnoun \& P. Quenel (2002): Programme de surveillance air et santé 9 villes - Surveillance des effets sur la santé liés à la pollution atmosphérique en milieu urbain - Phase II. Revue synthèse INVS, Paris, $24 \mathrm{p}$.

[9] Huijbregts M.A. (1999): Ecotoxical effect factors for the terrestrial environment in the frame of LCA. Univ. Amsterdam, Amsterdam, The Netherlands, $22 \mathrm{p}$.

[10] Moch A. \& I. Roussel (2000): Représentation et évaluation de la pollution atmosphérique dans l'agglomération de Dunkerque. Rapport APPA, Lille, France, $82 \mathrm{p}$.

[11] Diren, Ademe, CSTB \& LMH (2004): Les effets de la pollution atmosphérique sur le patrimoine bâti. <http://www.pays-de-laloire.drire.gouv.fr/Env/AI/AIe/8.pdf > (consulté le 05/03/04)

[12] O'Connor M. \& C.L. Spash (1999): Valuation and the environment Theory, method and practice. Edward Elgar, Cheltenham, UK, 300 p.

[13] Spash C.L. \& N. Hanley (1993): Cost-benefit analysis and the environment. Edward Elgar, Cheltenham, UK, 270 p.

[14] Huijbregts M.A. (2000a): Priority assessment of toxic substance in the frame of LCA - Time horizon dependency in toxicity potentials calculated with the multi-media fate, exposure and effect model USES-LCA. Univ. Amsterdam, Amsterdam, The Netherlands, $12 \mathrm{p}$. 
[15] Huijbregts M.A. (2000b): Spatially explicit characterization of acidifying and eutrophying air pollution in life-cycle assessment. J. Industrial Ecology, vol 4, n³, p. 125-142.

[16] Solomon S. \& D.L. Albritton (1992): Time-dependant ozone depletion potentials for short and long term forecast. Nature, vol 357, p. 33-37.

[17] Faucheux S. \& M. O'Connor (1998): Valuation for sustainable development - Methods and policy indicators. Edward Elgar, Cheltenham, $\mathrm{UK}, 350 \mathrm{p}$.

[18] Funtowicz S., M. O'Connor \& J. Ravetz (1997): Emergent complexity and ecological economics - Economy and ecosystems in change. In "Economy and Ecosystems in Change - Analytical and Historical Approaches". Edward Elgar, Cheltenham, UK, p. 75-95.

[19] Weber J.L. \& A. Vanolli (1986): Les Comptes du Patrimoine Naturel. Rapport Insee, Série D, n535-536, 552 p. 